\title{
Thrombosis of TAVI prosthesis-cause for concern or innocent bystander? A comment and review of currently available data
}

\author{
Stephan H. Schirmer ${ }^{1} \cdot$ Felix Mahfoud $^{1} \cdot$ Peter Fries $^{2} \cdot$ Bruno Scheller $^{1}$
}

Received: 30 November 2016/ Accepted: 1 December 2016/Published online: 19 December 2016

(C) Springer-Verlag Berlin Heidelberg 2016

Transcatheter aortic valve implantation (TAVI) has become an established treatment option for severe aortic stenosis in patients at high risk of surgical aortic valve replacement [1, 2]. Recent studies, such as PARTNER-2 [3] and NOTION [4] have expanded the possible use of TAVI to patients at intermediate surgical risk. With increasing life expectancy of patients undergoing TAVI, the issue of valve durability becomes increasingly important. As yet, there is a paucity of data on the antithrombotic regimen following TAVI, although reports on many thousands TAVI procedures have been published [5], demonstrating excellent outcomes in all risk categories [6]. Until recently, much investigated safety issues in TAVI were risk of access vessel complications [7, 8], stroke, or pacemaker implantation, all of which have decreased substantially [9-12], resulting in an increasing global uptake of the approach. Changes in prosthesis leaflet morphology and function shortly after TAVI only gained interest in 2014, when a review of single case reports identified 16 clinical events of transcatheter valve thrombosis during 2002-2012 [13]. Increasing trans-valvular gradients on echocardiography (from 10 to $42 \mathrm{mmHg}$ ) were noted in these patients presented with dyspnea as the most common symptom.

Stephan H. Schirmer

stephan.schirmer@uniklinikum-saarland.de

$1 \quad$ Klinik für Innere Medizin III

(KardiologieAngiologieInternistische Intensivmedizin), Universitätsklinikum des Saarlandes, 66421 Homburg/Saar, Germany

2 Klinik für Diagnostische und Interventionelle Radiologie, Universitätsklinikum des Saarlandes, 66421 Homburg/Saar, Germany
Anticoagulation with vitamin $\mathrm{K}$ antagonist (warfarin) effectively restored hemodynamics within 2 months.

When considering prosthetic valve deterioration, it is important not to mix structural, hemodynamic and clinical readouts, and endpoints. According to standardized endpoint definitions on TAVI by the Valve Academic Research Consortium, valve thrombosis is defined as "Any thrombus attached to or near an implanted valve that occludes part of the blood flow path, interferes with valve function, or is sufficiently large to warrant treatment" [14]. To this extent, recent studies used new generation computer tomography (CT) to visualize morphological changes (such as leaflet thickening or thrombosis) not visible in echocardiography [15]. These changes do not necessarily correlate with hemodynamic changes (i.e. rise in pressure gradient) and probably even less with clinical events, such as dyspnea, heart failure or stroke, although clinical endpoints do of course need larger studies and longer followup.

In 2015, reduced bioprosthetic leaflet motion was incidentally observed in a patient who had a stroke in a clinical trial investigating a novel transcatheter valve system (Portico valve). Subsequent analyses of available CT scans from this trial together with two registries were published in the same year [16]. Makkar et al. [16] reported reduced leaflet motion on CT in $40 \%$ (20 of 55 patients) in the clinical trial and $13 \%$ (17 of 132 patients) in the two registries. Notably, none of the patients on warfarin showed reduced leaflet motion. Leaflet motion in patients on dual platelet inhibition (aspirin and clopidogrel, DAPT) was normalized by initiation of anticoagulation. The authors also found a hint towards more strokes or transitory ischemic attacks (TIA) in patients with reduced valve leaflet motion ( 3 vs. 1 in patients with normal leaflet motion). Importantly, reduced leaflet motion occurred in 


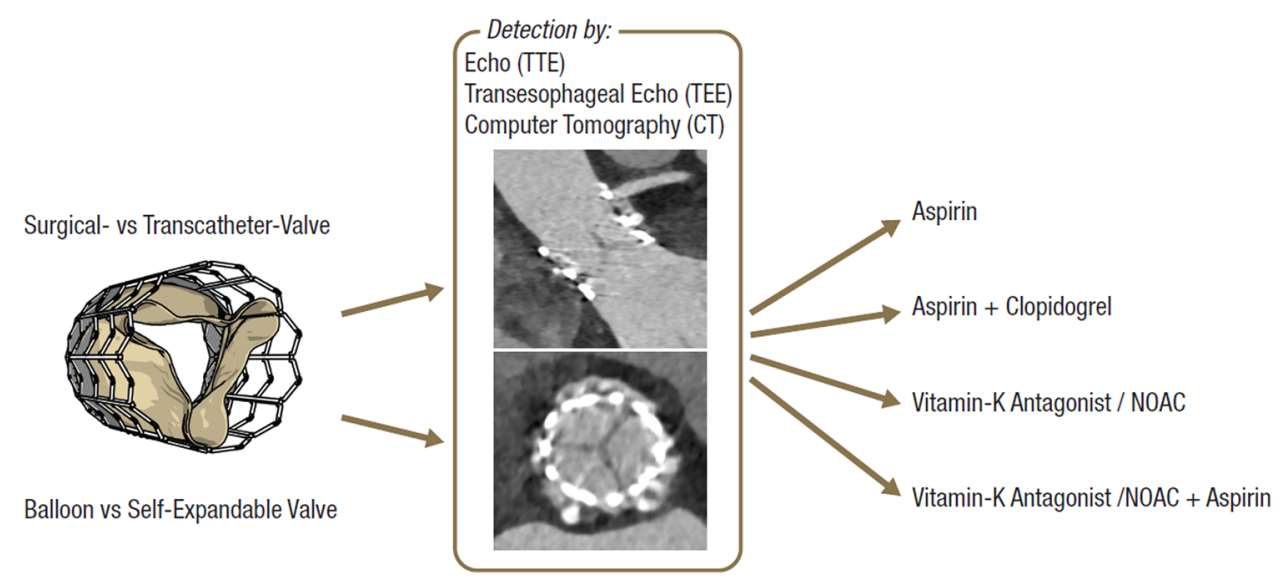

Fig. 1 The influence of prosthetic valve type (balloon vs. selfexpandable) and mode of implantation (surgical vs. transcatheter valve) (left side) possibly influences the course of leaflet alterations. These can most sensitively be detected by computer tomography,

both TAVI and surgically implanted valves and was not associated with increased transvalvular gradients as measured by echocardiography.

A recently published registry of 1521 patients after TAVI with serial echocardiographic follow-up reported the incidence of valve hemodynamic deterioration (VHD), defined as an increase of $\geq 10 \mathrm{mmHg}$ in transvalvular gradient compared to discharge [17]. The authors documented VHD in $4.5 \%$ of the patients. Next to procedural issues (valve-in-valve implantation [18], small valve size), the absence of anticoagulation was a predictor of VHD, suggesting morphological changes and possibly leaflet thrombus as the underlying mechanisms. In this study, functional (echocardiography) and not structural (CT) assessments were used. During a 4-year follow-up, no difference in (cardiovascular) death or stroke was observed.

The largest cohort of patients with transcatheter heart valve (THV) changes was published by the Milan group, who presented multicenter data on 4266 patients undergoing TAVI [19]. The authors defined THV dysfunction as a mean gradient of $20 \mathrm{mmHg}$ on echocardiography, and THV thrombosis when according changes visualized in echo, CT, or histopathology. While patients were not systematically screened, 26 THV thromboses $(0.6 \%)$ were noted, which was reported to be clinically significant (dyspnea) in two-thirds $(n=17)$. In these patients, the mean pressure gradient was described to formally fulfill the criteria of a relevant aortic stenosis $(41 \mathrm{mmHg})$. Anticoagulation normalized pressure gradients in the majority of the patients $(88 \%)$ within two months.

Routine multi-detector CT (MDCT) was performed in 460 consecutive patients in a Danish study 1 and 3 months following TAVI [20]. Hypo-attenuated leaflet thickening while transthoracic echo offers better functional insights and transesophageal echo allows a higher temporal resolution. Antithrombotic strategies currently under prospective evaluation are depicted on the right side

was regarded indicative of valve thrombosis. THV thrombosis was reported in $7 \%$ of the patients, of whom the majority was asymptomatic, but $18 \%$ showed clinical symptoms. Again, THV thrombosis was more common (relative risk 6.1, confidence interval: 1.9-19.8, $p<0.001$ ) in patients not on anticoagulant but antiplatelet therapy. Using MDCT and transesophageal echo showed reversal of valve thrombosis and function in $85 \%$ of patients by warfarin treatment.

In the current issue of the journal, Ruile et al. present follow-up data on TAVI prosthesis deterioration in relation to patient's antithrombotic regime [21]. A total of 51 patients with leaflet thickening as detected by MDCT were examined. Until May 2015, patients with leaflet thrombosis were treated with vitamin $\mathrm{K}$ antagonist (phenprocoumon) and clopidogrel for 3 months (22 out of 528 patients undergoing routine MDCT scans following TAVI). Following May 2015, in patients with leaflet thickening, anticoagulation was only initiated in an established indication for anticoagulation (e.g. atrial fibrillation, $n=9$ ), the remaining 22 patients were treated with DAPT. While leaflet thickening/restriction increased in the DAPT group, it regressed significantly in the anticoagulated group. The change in CT-derived morphological valvular pathologies was significantly different between the two groups analyzed. Of note, following discontinuation of anticoagulation, leaflet pathologies relapsed, with significant recurrences of leaflet restriction and thrombus extent. Interestingly, the change in pressure gradient as measured by echocardiography correlated with the change in leaflet restriction. However, none of the patients reported clinically apparent symptoms relative to THV thrombosis. Some of the findings of the current report are confirmatory of earlier analyses by the same group and by Makkar et al. 
[16] and Hansson et al. [20]. However, progression of leaflet thickening under DAPT and, particularly, possible recurrence after discontinuation of anticoagulation therapy are important novel findings. The authors published a smaller series ( $n=156$ CTs in TAVI (Sapien S3) patients) earlier this year, in which they report hypo-attenuated leaflet thickening to occur in 16 patients $(10.3 \%)$ [22]. Interestingly, in that study, valve thrombosis was not linked to lack of anticoagulation therapy at baseline, while it was reversible by initiation of anticoagulation therapy.

As acknowledged also by the authors, the non-randomized and non-prospective, single-center nature of the current study represent limitations. Therapeutic decisions were left at the discretion of the treating physician; therefore, treatment bias cannot be fully excluded. The case series including follow-up does, however, provide an excellent basis for further prospective, randomized trials comparing anticoagulation (vitamin $\mathrm{K}$ antagonist or NOAC [23]) with antiplatelet therapy in patients with TAVI. Several of these studies are currently enrolling patients, mostly with hard clinical endpoints (death, myocardial infarction, stroke, bleeding, thrombosis) (Table 1).

The question remains if the issues described are specific for TAVI bioprostheses or occur in surgical aortic valve replacement as well. In the latter, structural valve degeneration has been reported to occur at a rate of $20-30 \%$ after 10 years of implantation [24]. Reports on valve thrombosis in surgically inserted bioprosthesis vary in the literature and reach up to $5 \%$, but these data were acquired before MDCT became available and could, therefore, be higher. In a series of 397 explanted biological valves, Egbe et al. found bioprosthetic valve thrombosis at a rate of $11.6 \%$ [25]. Here, subtherapeutic INR was a strong predictor of valve thrombosis.

Notwithstanding the clinical relevance of the current findings, it is important to note that mid- to long-term clinical outcomes following TAVI have been excellent. Recent reports (presented at EuroPCR 2016 by Danny Dvir) on long-term follow-up of patients undergoing balloon-expandable first-generation valves, provide hints of valve degeneration (more regurgitation than stenosis) that were, interestingly, not linked to anticoagulant therapy but to the presence of comorbidities, such as chronic kidney disease. The authors reported a better than $90 \%$ valve patency up to 5 years followed by accelerated valve degeneration between 5 and 7 years. However, these findings have been questioned due to methodological flaws of the Kaplan-Meier analysis used including limited patient numbers at risk at the later time points [26].

As demonstrated in the long-term follow-up analysis of the PARTNER trial, 5-year function of TAVI prosthesis ( $n=3105$ patients) is good (i.e. no structural valve deterioration requiring surgery), providing reassurance about the long-term durability [27]. Particularly, there was no difference in transvalvular pressure gradient between the TAVI and the surgical group (mean gradient 10.7 vs. $10.6 \mathrm{mmHg}$ ). In the intermediate risk PARTNER 2 trial, pressure gradients were even lower following TAVI than after conventional surgery (2-year follow-up data available) [3].

What do the different outcome measures yielded by different diagnostic strategies tell us? To reliably detect leaflet thickening and valve thrombosis, CT would have to be performed on a routine basis in all patients. Transesophageal echocardiography is, however, superior in terms of temporal resolution. Because of the discrepancy between clinical outcomes and rate of leaflet thickening, functional analysis, i.e. (transthoracic) echocardiography, might be sufficient to identify those patients with hemodynamically relevant valve obstruction by thrombotic material. If currently ongoing studies provide evidence that anticoagulant therapy is indeed necessary, valve morphological and functional deterioration might (again) become rare. In the meantime, prescribing anticoagulant instead of antiplatelet therapy not only in patients with concomitant atrial fibrillation but in all patients following TAVI at low or intermediate bleeding risk might become an option (Fig. 1). Weighing the benefits for anticoagulation using the $\mathrm{CHA}_{2} \mathrm{DS}_{2}-\mathrm{Vasc}$ score may also be an option in TAVI patients without atrial fibrillation [28]. In patients with concomitant atrial fibrillation, combination of antiplatelet with anticoagulation therapy seems not to reduce ischemic events, but increases bleeding complications, as suggested by a recent retrospective analysis in 621 patients [29], indicating that the combination of anticoagulant with antiplatelet therapy may worsen outcome. Of note, relying on CT for a diagnosis of valve deterioration might be misleading in the end, owing to its morphological rather than functional character. The few clinical events demonstrated in currently available reports are in contrast to the apparent frequency of valve alterations. Regression of the parameters described following initiation of anticoagulation will also have to be scrutinized in a prospective fashion.

Findings on bioprosthetic valve deterioration are increasingly important when intermediate or low risk patients undergo TAVI and also surgical bioprosthesis implantation. Both, the ESC 2012 [30] and AHA 2014 [31] guidelines assign anticoagulation therapy only a class IIb indication following surgical aortic bioprosthesis implantation. Given the data on both transcatheter but also surgical valve deterioration, opting for a more aggressive strategy here might be necessary. 


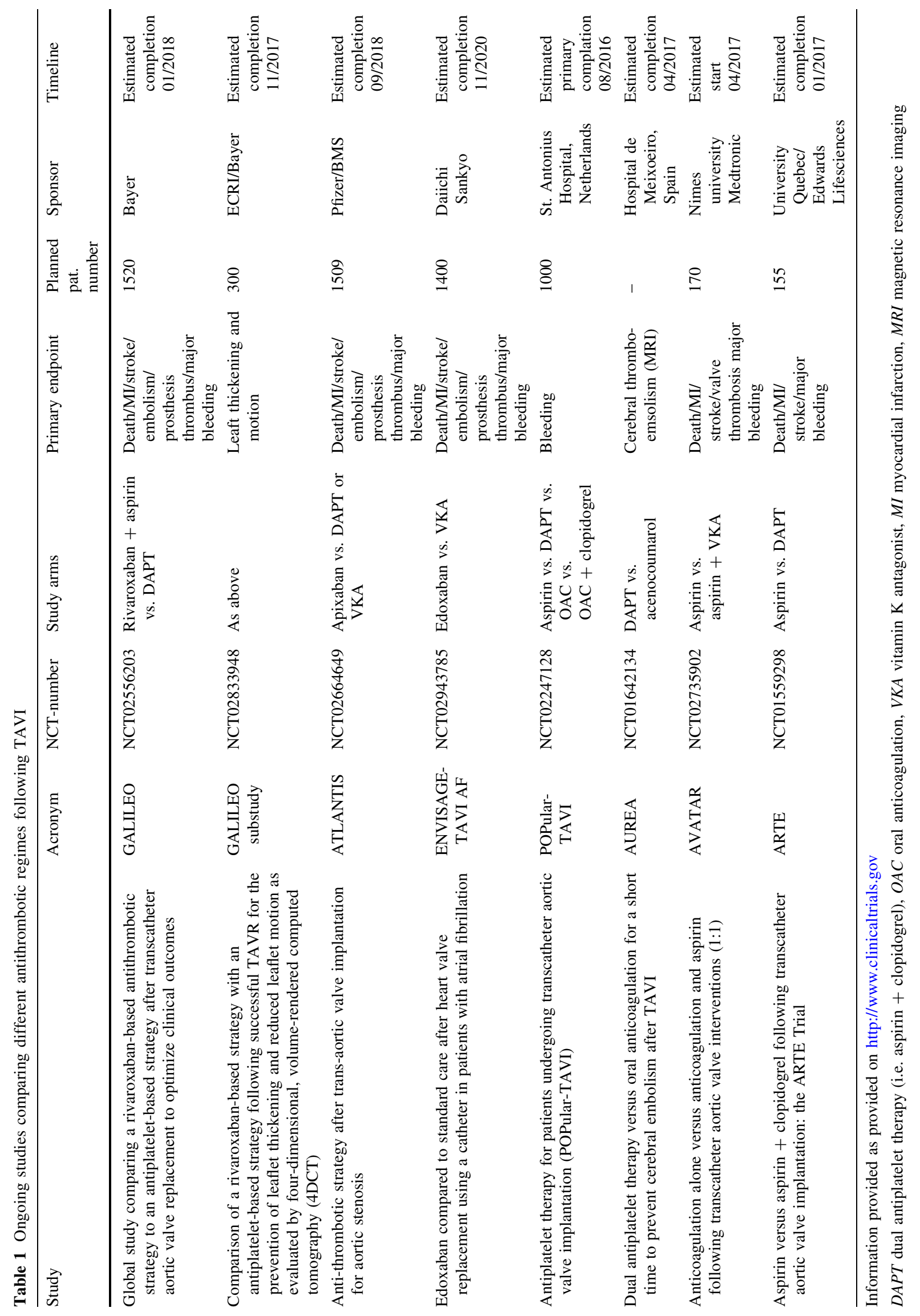




\section{References}

1. Haussig S, Schuler G, Linke A (2014) Worldwide TAVI registries: what have we learned? Clin Res Cardiol 103(8):603-612

2. Seiffert M, Sinning JM, Meyer A, Wilde S, Conradi L, VasaNicotera M, Ghanem A, Kempfert J, Hammerstingl C, Ojeda FM, Kim WK, Koschyk DH, Schirmer J, Baldus S, Grube E, Mollmann H, Reichenspurner H, Nickenig G, Blankenberg S, Diemert P, Treede H, Walther T, Werner N, Schnabel RB (2014) Development of a risk score for outcome after transcatheter aortic valve implantation. Clin Res Cardiol 103(8):631-640

3. Leon MB, Smith CR, Mack MJ, Makkar RR, Svensson LG, Kodali SK, Thourani VH, Tuzcu EM, Miller DC, Herrmann HC, Doshi D, Cohen DJ, Pichard AD, Kapadia S, Dewey T, Babaliaros V, Szeto WY, Williams MR, Kereiakes D, Zajarias A, Greason KL, Whisenant BK, Hodson RW, Moses JW, Trento A, Brown DL, Fearon WF, Pibarot P, Hahn RT, Jaber WA, Anderson WN, Alu MC, Webb JG (2016) Transcatheter or surgical aortic-valve replacement in intermediate-risk patients. N Engl J Med 374(17):1609-1620

4. Thyregod HG, Steinbruchel DA, Ihlemann N, Nissen H, Kjeldsen BJ, Petursson P, Chang Y, Franzen OW, Engstrom T, Clemmensen P, Hansen PB, Andersen LW, Olsen PS, Sondergaard L (2015) Transcatheter versus surgical aortic valve replacement in patients with severe aortic valve stenosis: 1-year results from the all-comers NOTION Randomized Clinical Trial. J Am Coll Cardiol 65(20):2184-2194

5. Mollmann H, Bestehorn K, Bestehorn M, Papoutsis K, Fleck E, Ertl G, Kuck KH, Hamm C (2016) In-hospital outcome of transcatheter vs. surgical aortic valve replacement in patients with aortic valve stenosis: complete dataset of patients treated in 2013 in Germany. Clin Res Cardiol 105(6):553-559

6. Biermann J, Horack M, Kahlert P, Schneider S, Nickenig G, Zahn R, Senges J, Erbel R, Wasem J, Neumann T (2015) The impact of transcatheter aortic valve implantation on quality of life: results from the German transcatheter aortic valve interventions registry. Clin Res Cardiol 104(10):877-886

7. Geis NA, Chorianopoulos E, Kallenbach K, Andre F, Pleger ST, Karck M, Katus HA, Bekeredjian R (2014) Feasibility of sheathless transfemoral aortic valve implantation in patients with small access vessel diameters. Clin Res Cardiol 103(10):775-780

8. Seidler T, Hunlich M, Puls M, Hasenfuss G, Jacobshagen C (2016) Feasibility and outcomes of interventional treatment for vascular access site complications following transfemoral aortic valve implantation. Clin Res Cardiol. doi:10.1007/s00392-0161038-1

9. Abdul-Jawad Altisent O, Ferreira-Gonzalez I, Marsal JR, Ribera A, Auger C, Ortega G, Cascant P, Urena M, Del Blanco BG, Serra V, Sureda C, Igual A, Rovira A, Gonzalez-Alujas MT, Gonzalez A, Puri R, Cuellar H, Tornos P, Rodes-Cabau J, GarciaDorado D (2016) Neurological damage after transcatheter aortic valve implantation compared with surgical aortic valve replacement in intermediate risk patients. Clin Res Cardiol 105(6):508-517

10. Kim WK, Liebetrau C, van Linden A, Blumenstein J, Gaede L, Hamm CW, Walther T, Mollmann H (2016) Myocardial injury associated with transcatheter aortic valve implantation (TAVI). Clin Res Cardiol 105(5):379-387

11. Samim M, Hendrikse J, van der Worp HB, Agostoni P, Nijhoff F, Doevendans PA, Stella PR (2015) Silent ischemic brain lesions after transcatheter aortic valve replacement: lesion distribution and predictors. Clin Res Cardiol 104(5):430-438

12. Weber M, Bruggemann E, Schueler R, Momcilovic D, Sinning JM, Ghanem A, Werner N, Grube E, Schiller W, Mellert F, Welz A, Nickenig G, Hammerstingl C (2015) Impact of left ventricular conduction defect with or without need for permanent right ventricular pacing on functional and clinical recovery after TAVR. Clin Res Cardiol 104(11):964-974

13. Cordoba-Soriano JG, Puri R, Amat-Santos I, Ribeiro HB, AbdulJawad Altisent O, del Trigo M, Paradis JM, Dumont E, Urena M, Rodes-Cabau J (2015) Valve thrombosis following transcatheter aortic valve implantation: a systematic review. Revista espanola de cardiologia (English ed) 68(3):198-204

14. Kappetein AP, Head SJ, Genereux P, Piazza N, van Mieghem NM, Blackstone EH, Brott TG, Cohen DJ, Cutlip DE, van Es GA, Hahn RT, Kirtane AJ, Krucoff MW, Kodali S, Mack MJ, Mehran R, Rodes-Cabau J, Vranckx P, Webb JG, Windecker S, Serruys PW, Leon MB (2012) Updated standardized endpoint definitions for transcatheter aortic valve implantation: the Valve Academic Research Consortium-2 consensus document (VARC-2). Eur J Cardiothorac Surg 42(5):S45-S60

15. Leetmaa T, Hansson NC, Leipsic J, Jensen K, Poulsen SH, Andersen HR, Jensen JM, Webb J, Blanke P, Tang M, Norgaard BL (2015) Early aortic transcatheter heart valve thrombosis: diagnostic value of contrast-enhanced multidetector computed tomography. Circ Cardiovasc Interv 8(4):e001596

16. Makkar RR, Fontana G, Jilaihawi H, Chakravarty T, Kofoed KF, de Backer O, Asch FM, Ruiz CE, Olsen NT, Trento A, Friedman J, Berman D, Cheng W, Kashif M, Jelnin V, Kliger CA, Guo H, Pichard AD, Weissman NJ, Kapadia S, Manasse E, Bhatt DL, Leon MB, Sondergaard L (2015) Possible subclinical leaflet thrombosis in bioprosthetic aortic valves. $N$ Engl $\mathrm{J}$ Med 373(21):2015-2024

17. Del Trigo M, Munoz-Garcia AJ, Wijeysundera HC, NombelaFranco L, Cheema AN, Gutierrez E, Serra V, Kefer J, Amat-Santos IJ, Benitez LM, Mewa J, Jimenez-Quevedo P, Alnasser S, Garcia Del Blanco B, Dager A, Abdul-Jawad Altisent O, Puri R, CampeloParada F, Dahou A, Paradis JM, Dumont E, Pibarot P, Rodes-Cabau J (2016) Incidence, timing, and predictors of valve hemodynamic deterioration after transcatheter aortic valve replacement: multicenter registry. J Am Coll Cardiol 67(6):644-655

18. Milburn K, Bapat V, Thomas M (2014) Valve-in-valve implantations: is this the new standard for degenerated bioprostheses? Review of the literature. Clin Res Cardiol 103(6):417-429

19. Latib A, Naganuma T, Abdel-Wahab M, Danenberg H, Cota L, Barbanti M, Baumgartner H, Finkelstein A, Legrand V, de Lezo JS, Kefer J, Messika-Zeitoun D, Richardt G, Stabile E, Kaleschke G, Vahanian A, Laborde JC, Leon MB, Webb JG, Panoulas VF, Maisano F, Alfieri O, Colombo A (2015) Treatment and clinical outcomes of transcatheter heart valve thrombosis. Circ Cardiovasc Interv 8(4):e001779

20. Hansson NC, Grove EL, Andersen HR, Leipsic J, Mathiassen ON, Jensen JM, Jensen KT, Blanke P, Leetmaa T, Tang M, Krusell LR, Klaaborg KE, Christiansen EH, Terp K, Terkelsen CJ, Poulsen SH, Webb J, Botker HE, Norgaard BL (2016) Transcatheter aortic valve thrombosis: incidence, predisposing factors, and clinical implications. J Am Coll Cardiol 68(19):2059-2069

21. Ruile P, Jander N, Blanke P, Schoechlin S, Reinohl J, Gick M, Rothe J, Langer M, Leipsic J, Buettner HJ, Neumann FJ, Pache G (2016) Course of early subclinical leaflet thrombosis after transcatheter aortic valve implantation with or without oral anticoagulation. Clin Res Cardiol. doi:10.1007/s00392-016-1052-3

22. Pache G, Schoechlin S, Blanke P, Dorfs S, Jander N, Arepalli CD, Gick M, Buettner HJ, Leipsic J, Langer M, Neumann FJ, Ruile P (2016) Early hypo-attenuated leaflet thickening in balloon-expandable transcatheter aortic heart valves. Eur Heart $\mathbf{J}$ 37(28):2263-2271

23. Yadlapati A, Groh C, Malaisrie SC, Gajjar M, Kruse J, Meyers S, Passman R (2016) Efficacy and safety of novel oral 
anticoagulants in patients with bioprosthetic valves. Clin Res Cardiol 105(3):268-272

24. Pibarot P, Dumesnil JG (2009) Prosthetic heart valves: selection of the optimal prosthesis and long-term management. Circulation 119(7):1034-1048

25. Egbe AC, Pislaru SV, Pellikka PA, Poterucha JT, Schaff HV, Maleszewski JJ, Connolly HM (2015) Bioprosthetic valve thrombosis versus structural failure: clinical and echocardiographic predictors. J Am Coll Cardiol 66(21):2285-2294

26. Capodanno D (2016) Transcatheter aortic valve durability and the dark side of Kaplan-Meier analysis. EuroIntervention 12(7):821-822

27. Mack MJ, Leon MB, Smith CR, Miller DC, Moses JW, Tuzcu EM, Webb JG, Douglas PS, Anderson WN, Blackstone EH, Kodali SK, Makkar RR, Fontana GP, Kapadia S, Bavaria J, Hahn RT, Thourani VH, Babaliaros V, Pichard A, Herrmann HC, Brown DL, Williams M, Akin J, Davidson MJ, Svensson LG (2015) 5-Year outcomes of transcatheter aortic valve replacement or surgical aortic valve replacement for high surgical risk patients with aortic stenosis (PARTNER 1): a randomised controlled trial. Lancet 385(9986):2477-2484

28. Cerit L (2016) Transcatheter Aortic Matryoshka Doll. Thrombosis. Clin Res Cardiol. doi:10.1007/s00392-016-1057-y
29. Abdul-Jawad Altisent O, Durand E, Munoz-Garcia AJ, NombelaFranco L, Cheema A, Kefer J, Gutierrez E, Benitez LM, AmatSantos IJ, Serra V, Eltchaninoff H, Alnasser SM, Elizaga J, Dager A, Garcia Del Blanco B, Ortas-Nadal Mdel R, Marsal JR, Campelo-Parada F, Regueiro A, Del Trigo M, Dumont E, Puri R, Rodes-Cabau J (2016) Warfarin and antiplatelet therapy versus warfarin alone for treating patients with atrial fibrillation undergoing transcatheter aortic valve replacement. JACC Cardiovasc Interv 9(16): 1706-1717

30. Vahanian A, Alfieri O, Andreotti F, Antunes MJ, BaronEsquivias G, Baumgartner H, Borger MA, Carrel TP, De Bonis M, Evangelista A, Falk V, Iung B, Lancellotti P, Pierard L, Price S, Schafers HJ, Schuler G, Stepinska J, Swedberg K, Takkenberg J, Von Oppell UO, Windecker S, Zamorano JL, Zembala M (2012) Guidelines on the management of valvular heart disease (version 2012). Eur Heart J 33(19):2451-2496

31. Nishimura RA, Otto CM, Bonow RO, Carabello BA, Erwin JP 3rd, Guyton RA, O'Gara PT, Ruiz CE, Skubas NJ, Sorajja P, Sundt TM 3rd, Thomas JD (2014) 2014 AHA/ACC guideline for the management of patients with valvular heart disease: executive summary: a report of the American College of Cardiology/ American Heart Association Task Force on Practice Guidelines. J Am Coll Cardiol 63(22):2438-2488 